\title{
Um Retorno a Schiller: "A beleza é a liberdade na aparência" - Estética como Desafio para o Modo Moderno de Pensar ${ }^{1}$
}

Schiller Revisited: "Beauty is Freedom in Appearance" - Aesthetics as a Challenge to the Modern Way of Thinking

by Wolfgang Welsch $^{2}$

Tradução de Vitor Luiz Rigoti dos Anjos ${ }^{3}$

Resumo: Este ensaio reavalia a ideia de beleza de Schiller como "liberdade na aparência", segundo apresentada em Kallias ou Sobre a Beleza (1793), no contexto do pensamento pré-moderno e moderno que se baseou em uma divisão fundamental entre natureza e liberdade, mundo e homem. A afirmação de Schiller de que a beleza natural resulta da liberdade na natureza preenche esta lacuna. Sua sugestão é confirmada pela ciência moderna. A visão de Schiller é recomendada e defendida como uma forma de escapar da intolerância moderna.

Palavras-chave: Beleza, Crítica do Juizo, dualismo, ética do respeito, liberdade, Goethe, Hegel, Kallias ou Sobre a Beleza, Kant, Cartas sobre a Educação Estética do Homem, modernidade, natureza, objetividade, Schiller, autoorganização, subjetivismo.

Abstract: This essay re-evaluates Schiller's idea of beauty as "freedom in appearance," as brought forward in his Kallias or On Beauty (1793), against the backdrop of early modern and modern thinking that based itself on a fundamental split between nature and freedom, world and man. Schiller's claim that natural beauty results from freedom in nature bridges this 
gap. His suggestion is confirmed by modern science. Schiller's view is recommended and defended as a way of escaping modern bigotry.

Keywords: Beauty, Critique of Judgment, dualism, ethics of respect, freedom, Goethe, Hegel, Kallias or on Beauty, Kant, Letters on the Aesthetic Education of Man, modernity, nature, objectivity, Schiller, self-organization, subjectivism.

\section{Considerações Introdutórias}

a. Uma sugestão implícita de estética na era moderna: conectividade, não-inocência do homem com o mundo

Na primeira metade da década de 1770, Kant escreveu uma frase muito interessante: "As coisas bonitas indicam que o homem se encaixa no mundo" ". Caso esta afirmação seja verdadeira, então a estética tem a chance de ganhar grande importância para o pensamento moderno. Pois a estética, assim, tem o potencial de tratar e até mesmo de superar o erro fundamental sobre o qual o modo moderno e contemporâneo de pensar se baseia, a saber, o pressuposto de que existe uma lacuna intransponível entre os humanos e o mundo, por representarem ordens completamente diferentes: res extensa por parte do mundo; res cogitans por parte do humano.

Esta foi, de fato, a novidade fundamental que se desenvolveu junto com o pensamento pré-moderno: a de que o mundo não é tingido pelo espírito de forma nenhuma, e sim radicalmente irracional e determinado apenas pela extensão, pela matéria e por leis puramente mecânicas, enquanto os seres humanos ainda eram considerados como caracterizados pela racionalidade e pelo pensamento. Isto resultou em uma lacuna supostamente fundamental entre os seres humanos e o mundo, o dualismo notório homem-mundo. Diante de um mundo intrinsecamente sem espírito, o ser humano, como um ser intrinsecamente espiritual, poderia ser apenas um ser não-mundano.

Devido a essa heterogeneidade putativa entre seres humanos e mundo, os seres humanos seriam apenas capazes de produzir um mundo de acordo com a sua imaginação e de modo nenhum poderiam reconhecer o mundo real. A relação humana com o mundo tinha que ser construtivista em princípio, não realista; 
basta pensar na filosofia teórica de Kant. Desde aquela época, o pensamento moderno buscou um subjetivismo fundamental independentemente se ele tivesse um rosto transcendental ou historicista ou social. Na sua agenda padrão, a filosofia moderna mostrou sua marca de nascença subjetivista a partir da época de Kant através da filosofia analítica contemporânea.

A agenda subterrânea da filosofia moderna, no entanto, consistiu em superar esse dualismo e em desenvolver, em vez de uma dicotomia entre humanos e mundo, uma nova compreensão da face mundana dos humanos. Contudo, por muito tempo todas as tentativas em alcançar isto estiveram condenadas ao fracasso. Talvez a transição ocorra apenas em nossos dias ${ }^{5}$.

A estética - disciplina aparentemente aleatória da filosofia opera, caso a instrução kantiana citada no início seja verdadeira, em sua própria maneira nesta tarefa implícita e também extremamente importante de demonstrar que os seres humanos pertencem ao mundo. Isto é o que quero deixar claro a seguir, olhando para Schiller.

b. A tarefa da estética de acordo com Kant e como Kant falhou em cumpri-la por causa de sua atitude subjetivista

Primeiro, vamos primeiro olhar para Kant uma vez mais. Como eu disse, o Kant pré-crítico entendeu a beleza como um fenômeno que, em contraste com a visão padrão de dualidade, fornece evidência da nossa congruência com o mundo.

O Kant crítico, porém, começou a elaborar a lógica do dualismo. Em sua Crítica da Razão Pura (1781), mostrou que o mundo físico representa um nexo estritamente legal de aparências seguindo os princípios do entendimento puro. Em sua Crítica da Razão Prática (1788), ele então explicou como, para os humanos como seres morais, não esta ordem física e sim a ordem muito diferente da liberdade é crucial. Daqui nasceu a grande questão de como estas duas ordens podem caminhar juntas, e como, em particular, os atos de liberdade são possíveis em um mundo determinista. 
Neste problema, é óbvio que o dualismo do pensamento moderno aparece em forma concisa. Kant tentou fornecer uma solução na sua obra Crítica do Juízo (1790) e assim designou esta terceira crítica como "mediando a conexão das duas partes da filosofia em um todo" . O fenômeno da beleza, por um lado, e o do orgânico, por outro, deve possibilitar "uma transição [...] do domínio dos conceitos de natureza para o domínio do conceito de liberdade" $\mathrm{e}$, assim, testemunhar que temos o direito de assumir uma congruência entre nossas expectativas racionais e a estrutura do mundo. Nesta forma, devemos ter certeza de que nós humanos não somos, como declarado pela suposição padrão do pensamento moderno, profundamente estranhos ao mundo, mas, como Kant escrevera vinte anos antes, prontamente "pertencentes ao mundo."

No entanto, o modo como Kant enunciou este papel do belo foi infeliz. Ele enfatizou demais a subjetividade do juízo do gosto. Sublinhar a subjetividade é geralmente o defeito de suas concepções filosóficas, especialmente da sua teoria do conhecimento, onde todas as afirmações pela objetividade são reduzidas ao cumprimento de exigências subjetivas. Paralelamente, a alegria estética do belo, segundo Kant, também deve resultar exclusivamente do cumprimento da nossa intenção cognitiva geral, que é alcançar uma harmonia entre sensibilidade e compreensão ${ }^{8}$. Porém, ao argumentar desta forma, Kant obviamente perdeu o aspecto que, conforme o seu pensamento anterior, deve ser decisivo para a beleza, isto é, a experiência de uma congruência com o mundo. $\mathrm{O}$ belo então interpretado em termos meramente subjetivistas só permite experimentar a congruência dos poderes do sujeito, não experimentar uma congruência com o mundo.

O que falta em Kant geralmente, na epistemologia e na estética, é um olhar para as origens dos nossos padrões cognitivos. De onde foi que nós os obtivemos? Por que eles são como são? A resposta não é difícil. Estes padrões se desenvolveram no decorrer da evolução em alinhamento com o mundo. Por isso o mundo já está inscrito neles. Em consequência, há um ajuste entre esses padrões e a estrutura do mundo, e esta é a razão pela qual a beleza, sendo baseada em tais padrões, permite-nos experimentar que nós "pertencemos ao mundo." 
Não estando ciente disto, Kant foi incapaz de apresentar o belo como um fenômeno que demonstra que pertencemos ao mundo. Portanto, ao longo de suas páginas, a Crítica do Juizo simplesmente não atinge o que pretendia fazer: expor a correspondência entre o ser humano e o mundo.

Como eu disse, o subjetivismo é o cerne da filosofia kantiana. Seus sucessores, entretanto, inicialmente viram o subjetivismo principalmente como uma conquista e não como um problema e até aumentaram aquela perspectiva, especialmente Fichte e os primeiros românticos.

Apenas alguns se opuseram a esta tendência e consideraram o subjetivismo como uma meia verdade, no máximo. Paradigmaticamente, foi assim que Hegel fez. Ele repreendeu o idealismo subjetivo iniciado por Kant como um idealismo "insosso", "tolo", e até "filisteu". Todo o esforço de Hegel foi o de ultrapassar este "mau idealismo dos tempos modernos"10. Também Goethe lamentou em seus últimos anos: "Todo o meu tempo fugiu de mim, pois ele estava totalmente envolvido em uma direção subjetiva, enquanto que eu, com minha busca objetiva, estava em desvantagem e fiquei completamente só."11

\section{Schiller: beleza e liberdade}

Voltemo-nos agora para Schiller. Ele também compartilhou o desconforto com o subjetivismo kantiano; ele insistiu na objetividade da beleza. Particularmente interessante é a maneira que Schiller tentou demonstrar essa objetividade. Ele o fez conectando a beleza à liberdade. A beleza, segundo Schiller, é a "liberdade na aparência." Se esta fórmula for consistente, então pode-se dizer de antemão que o problema Crítica do Juízo se dissolve, pois uma natureza que produz a beleza já contém em si traços da liberdade. Daí que a realização da liberdade humana dentro da natureza não é problema nenhum; ao contrário, a liberdade representa um fator contínuo entre o mundo e os seres humanos. Segue-se que a estética pode ajudar a superar o beco sem saída do dualismo moderno. 
Vamos agora ver em detalhes como Schiller tornou isto plausível. Refiro-me às cartas que ele escreveu para seu amigo Gottfried Körner em 1793, cartas que ele intitulou Kallias ou Sobre a Beleza ${ }^{12}$. Na minha opinião, o conceito desenvolvido nestas cartas (que infelizmente foram publicadas só muito mais tarde, em 1847) é de extrema importância, muito mais do que a ideia proferida na obra mais famosa Cartas sobre a Educação Estética do Homem publicada em 1795.

\section{a. Regularidade, liberdade e beleza}

Primeiro, Schiller afirma que experimentamos como belas essas coisas naturais cuja formação é baseada em uma regra. Quando consideramos uma folha, imediatamente recebemos a impressão de que as partes múltiplas da folha atingiram seu astuto arranjo seguindo uma regra ${ }^{13}$. Se esta ordem desaparecesse, nós não mais julgaríamos a folha como bela. Então, primeiramente, a experiência da beleza é baseada na impressão de regularidade.

Em segundo lugar, esta regra não deve ser imposta ao objeto a partir de fora, mas derivar do próprio objeto ${ }^{14}$. Deve-se ter a impressão de que a regra e a formação correspondente "saíram livremente da própria coisa"15. Neste caso, o objeto aparece como autodeterminado, autorregulado, livre ${ }^{16}$.

Se ambas condições estiverem satisfeitas, isto é, se percebemos o objeto como seguindo uma regra imposta por si mesmo, então experimentamos o objeto como belo. Portanto, a experiência da beleza registra a liberdade. A beleza é um criptograma de liberdade ${ }^{17}$. A fórmula de Schiller para isto é: "A beleza é a liberdade na aparência"18. Esta fórmula não tem um significado restritivo. Schiller não quer dizer que, no caso de beleza, a liberdade ocorra apenas na forma imprópria de um fenômeno (enquanto que, em sua essência, a liberdade é algo inteligível), mas que, em um sentido absolutamente positivo, a liberdade está realmente aparecendo, está vindo à tona, manifestando-se, tornando-se evidente. A beleza é a real experiência da liberdade através da percepção ${ }^{19}$. 


\section{b. Objetividade}

É importante para Schiller que a sua explicação da percepção da beleza como liberdade garante, ao contrário do Kant, a objetividade da beleza. Isso porque a regularidade que é o testemunho da liberdade e simultaneamente a razão da beleza é um aspecto objetivo do próprio objeto, pertencente a ele independentemente se nós a percebemos ou não ${ }^{20}$. Por isso, ela é independente do sujeito, um aspecto verdadeiramente objetivo. c. Liberdade em todos os lugares, ou "no mundo
estético todo ser natural é um cidadão livre"

Schiller, em seguida, faz dois movimentos. Primeiro, ele desmascara a experiência da beleza como uma experiência de liberdade. Chamamos de belos a esses objetos que mostram liberdade. Em segundo lugar, ele transfere o caráter de liberdade da esfera humana para o mundo natural; ele vê que lá isso já ocorre. Assim, a experiência da beleza nos leva além de strettos antrópicos; a liberdade não é de forma nenhuma um fenômeno apenas humano, mas também natural. Schiller desenvolve uma ontologia geral da liberdade que compreende não só a esfera da ação humana, mas também o reino das coisas, das entidades naturais e das culturais.

Cito uma passagem mais longa:

Quando de fato se diz que uma pessoa está belamente vestida? Quando nem a roupa por meio do corpo, nem o corpo por meio da roupa, sofre nada em respeito à sua liberdade; quando a roupa aparenta como se ela não tivesse nada a ver com o corpo e mesmo assim cumpre o seu propósito ao máximo. A beleza - ou melhor, o gosto - considera todas as coisas como fins em si mesmas e não tolera de modo nenhum que um sirva ao outro como meio, ou que carregue o jugo. No mundo estético, todo ser natural é um cidadão livre, que tem direitos iguais com o que é mais nobre, e não pode sequer ser obrigado pelo bem do todo, mas deve consentir com tudo. No mundo estético, que é totalmente diferente da república platônica mais perfeita, até a jaqueta que eu carrego sobre meu corpo exige respeito de mim para sua liberdade, e deseja de mim, como um servo envergonhado, que eu não deixe 
ninguém notar que ela serve a mim. Por essa razão, contudo, ela também me promete, reciprocamente, empregar a sua liberdade de forma tão modesta que a minha não sofra nada então; e quando ambos mantiverem sua palavra, assim também o mundo inteiro dirá que eu estou belamente vestido ${ }^{21}$.

Então Schiller sugere, como afirmei anteriormente, uma extensão da liberdade. Ele expande sua ocorrência para além da moralidade humana, à natureza e aos artefatos. Esteticamente, uma pessoa descobrirá a liberdade em todos os lugares: "O gosto considerará todas [grifo meu] as coisas como fins em si mesmas" $"$. Toda a natureza é um reino da liberdade: "Toda bela criatura da natureza" é "uma cidadã sortuda que me desafia: Seja livre como eu o sou"23.

A liberdade é um fenômeno natural antes de ser um fenômeno humano. Assim, cada ser natural deve ser reconhecido e ser respeitado como um "cidadão livre." A diferença entre o ser humano e a natureza não é a diferença entre liberdade e falta de liberdade, pois ambos possuem liberdade. Tudo é, estritamente falando, uma instância de liberdade. Que a liberdade não seja um privilégio humano, mas sim um fato natural é o que a experiência estética descobre e recomenda fortemente a levar em conta.

Desta forma, a experiência estética leva a uma ética da liberdade. Devemos ver todas as coisas como figuras da liberdade e, portanto, tratá-las com respeito. A liberdade é o caráter básico do Ser. A atitude estética capta esse caráter básico e recomenda uma ética do respeito universal. Aqui Schiller obviamente transcende os limites ocidentais e defende uma perspectiva ética que é mais conhecida no Leste da Ásia (cf. Taoísmo e Budismo). Devemos tratar todos os seres, todos os nossos concidadãos naturais neste mundo, com igual respeito. Com bastante frequência, Schiller também inverte o padrão ocidental, segundo o qual a liberdade é, em primeiro lugar, a própria liberdade da pessoa (basta lembrar a concepção de Fichte) e só posteriormente a liberdade do outro, quando ele afirma: "A primeira lei de bons modos é: permita a liberdade dos outros. A segunda: Mostre liberdade você mesmo." $24 \mathrm{E}$ Schiller comenta: "O cumprimento exato de ambas é um 
problema infinitamente difícil, mas os bons modos o exigem continuamente, e ele sozinho gera o homem realizado do mundo" 25 .

\section{d. Ilusão estética ou liberdade real?}

Para concluir esta interpretação de Schiller, quero abordar duas questões intimamente relacionadas. $O$ que a filosofia de liberdade desenvolvida nas cartas de Kallias aparenta ser em comparação com a obra posterior Cartas sobre a Educação Estética do Homem? Schiller realmente vê a liberdade como uma propriedade objetiva das coisas naturais (ou pelo menos das coisas belas na natureza) ou ele apenas quer que as consideremos como figuras da liberdade, embora na realidade elas não o sejam (pois isso não pode ser reivindicado em sentido estrito)? ${ }^{26} \mathrm{O}$ "reino do gosto",27 esboçado nas cartas de Kallias seria no fim apenas um reino da ilusão, como é o caso do "estado estético" 28 proclamado em Cartas sobre a Educação Estética do Homem?

A diferença entre os dois conceitos é substancial. Nas cartas de Kallias, Schiller não se restringe, como ele faz nas Cartas sobre a Educação Estética do Homem, ao mundo humano, e muito menos a "apenas alguns círculos seletos",29, mas lida com a liberdade precisamente na medida em que ela vai além do reino humano. E, de modo mais importante, ele entende e recomenda a liberdade não apenas como aparência ou como uma ideia reguladora ou similar. Ele não quer dizer que se deve apenas considerar as coisas naturais como formas da liberdade, embora elas não o sejam de fato. Em vez disso, ele está convencido de que tudo é um exemplo de liberdade, e que se deve levar isso em conta.

\section{Avaliação dos conceitos de Schiller}

Passemos agora a uma avaliação crítica da posição de Schiller.

$$
\text { a. "Liberdade" }
$$


Uma primeira questão diz respeito à forma como Schiller compreende a liberdade. Schiller a vê em ordem onde quer que a forma de um objeto natural for causada por uma regra autoimposta. A folha foi um exemplo disso. A ideia de Schiller é apropriada e suficiente?

O núcleo da percepção de liberdade de Schiller é que a forma do objeto não é simplesmente forçada por pressão externa, mas deve-se a uma atividade intrínseca do objeto. Com certeza seria um exagero dizer que a forma resulta exclusivamente de tal atividade; é evidente que os fatores externos também desempenham um papel. O ponto decisivo é que há uma interação na qual a energia da forma apropriada do objeto tem sua parte e que esta é reconhecível no resultado. Schiller fala da liberdade onde tal autoformação está em jogo e é perceptível.

Com entidades orgânicas, é certamente verdade que elas devem sua forma aos atos de autoformação. Sua formação é causada não só por fatores externos, mas também por fatores internos; na terminologia moderna, pelo genoma que predefine certos passos de crescimento e formação, que são então aplicados em interação com o ambiente.

De fato, o indivíduo não se inventa do zero, mas percebe o modo de sua espécie sob determinadas condições ambientais. Porém a autocriação completa não está em debate, de qualquer forma, quando falamos de liberdade. (A liberdade não deve ser equacionada com arbitrariedade ou com "adesionismo pleno" ${ }^{\text {, }}$.) Além disso, o próprio modo da espécie surgiu em um processo que envolve a liberdade. As regras final e geneticamente ancoradas foram desenvolvidas pela própria espécie ao longo do tempo, em sintonia com as condições externas. Em resumo, tanto o aparecimento das propriedades da espécie quanto a formação de exemplares individuais desta espécie implicam elementos de autoformação. Assim, a ideia de Schiller está certa à medida que concernem os seres orgânicos.

\section{b. Tudo que é natural é belo?}

É claro, isto conduz diretamente a um problema. A visão de liberdade de Schiller pode ser aplicada a todas as entidades 
orgânicas, mas experienciamos apenas alguns seres orgânicos como belos. Se o nosso senso de beleza fosse, como Schiller sugere, geralmente causado pela percepção de autoformação, então teríamos de experienciar todas as entidades orgânicas como belas. Porém, não o fazemos. Algo parece estar errado com a concepção de Schiller.

A melhor resposta a essa objeção parece ser a seguinte. Schiller imagina um tipo de beleza (e cada vez mais somente este tipo) que é essencialmente um indicador da liberdade. Tudo o que importa para ele é descobrir traços de liberdade, e, onde quer que ele os reconheça, ele fala da beleza. Pode-se avaliar isso como unilateralidade ou mesmo idiossincrasia, mas deve-se também ter em mente que o conceito e o sentido de beleza não são fixos per se, mas são cultural e historicamente variáveis. Schiller, vivendo na era da liberdade e inicialmente entusiasmado com a Revolução Francesa ${ }^{31}$, simplesmente busca a liberdade em todo lugar e faz da beleza aquilo que detecta a liberdade. Assim, ele deve, para ser consistente, considerar qualquer forma orgânica, caso ela apenas mostre traços de autoformação, como bela ${ }^{32}$. Este é certamente um modo muito especial de se avaliar a beleza, mas que também pode ser bem compreendido. Por exemplo, muitos biólogos, em virtude de seus conhecimentos especiais, consideram as criaturas como belas em cada traço que o homem comum prefere rejeitar como feio.

\section{c. A auto-organização e a liberdade na natureza}

A proposta de Schiller é ver os elementos da liberdade em toda parte da natureza e, assim, considerar e tratar cada ser natural como um cidadão livre, superior? A ciência moderna comprova amplamente que Schiller está correto. Ela ressalta que em muitos níveis a natureza exibe traços de liberdade. Isto é bem conhecido em nível micro; o mundo quântico não é determinista, e sim mostra espontaneidade em muitos aspectos. O mesmo se aplica ao nível macro. A autorreferência e a autoorganização, formas fundamentais de liberdade a serem encontradas no mundo físico, são os princípios mais básicos segundo os quais a natureza produz as suas estruturas de ordem, desde galáxias passando por organismos até as formações 
sociais. Assim, a liberdade é um princípio fundamental e universal da natureza (ou evolução) e da evolução cósmica, biótica e cultural ${ }^{33}$. Schiller estava completamente certo em afirmar que a liberdade já ocorre na natureza.

Além disso, a tese de Schiller que a liberdade natural encontra sua expressão na beleza é apoiada pela ciência contemporânea. Cientistas descobriram que os tipos notáveis de beleza são baseados no fato de que as entidades em questão alcançaram sua forma através de processos de auto-organização ${ }^{34}$. É o caso, por exemplo, dos padrões de crescimento graças ao "ângulo áureo," a aplicação da proporção áurea a um círculo. Exemplos disso são as escamas das pinhas ou as sementes de girassóis, mas também a disposição das manchas circulares da cauda do pavão ou a estrutura das conchas ${ }^{35}$. Em tais casos, o nosso senso de beleza responde à autossimilaridade que resulta de processos de feedback e, portanto, é um detetor de auto-organização. Assim, a teoria de Schiller é confirmada pela ciência contemporânea; a beleza resulta da auto-organização ${ }^{36}$. Em suma, Schiller não está apenas correto em afirmar que a liberdade já ocorre na natureza $^{37}$, mas também está igualmente justificado em sua afirmação de que a estética pode servir como indicador a esse fato.

\section{d. A concepção de estética de Schiller supera o modo moderno e dualista de pensar}

Finalmente, voltemos às deliberações iniciais. Como eu disse, a estética é capaz de curar o erro básico do modo moderno de pensar, o qual é a estrita oposição entre os seres humanos e o mundo que resulta de uma disparidade ontológica supostamente fundamental entre os dois. Nesse meio tempo, vimos como a estética de Schiller, conforme descrito nas cartas de Kallias, fornece uma solução. Ela supera o dualismo moderno mostrando que a natureza não é simplesmente determinista, ela inclui fenômenos da liberdade, e, portanto, não é categoricamente oposta ao reino da liberdade humana, mas aberta a ele $^{38}$.

Schiller descreve, do ponto de vista estético, um monismo de liberdade em vez do dualismo moderno. Se o mundo já contém dimensões de liberdade, então o homem não deve confrontar o 
mundo como um estrangeiro, mas pode, como Schiller diz, acolher e respeitar as coisas naturais como cidadãos iguais, como instâncias afins de liberdade que inversamente lhe convocam: "Seja livre como eu o sou." Então a oposição do homem e do mundo foi superada, e nós, humanos, podemos progredir na aliança com os nossos concidadãos naturais.

\section{Referência bibliográfica}

CRAMER, Friedrich. Chaos und Ordnung: Die komplexe Struktur des Lebendigen. Stuttgart: Deutsche Verlags-Anstalt, 1989.

.; KAEMPFER, Wolfgang, Die Natur der Schönheit: Zur Dynamik der schönen Formen. Frankfurt/Main: Insel, 1992.

GOETHE, Johann Wolfgang. Sämtliche Werke nach Epochen seines Schaffens (Münchner Ausgabe), Karl Richter et al (ed.) Vol. 19: Johann Peter Eckermann, Gespräche mit Goethe in den letzten Jahren seines Lebens, ed. Heinz Schlaffer. Munique: Hanser, 1986.

HEGEL, Friedrich Wilhelm. Enzyklopädie der philosophischen Wissenschaften im Grundrisse I [1830], Werke, vol. 8. Frankfurt/Main: Suhrkamp, 1986. . Vorlesungen über die Geschichte der Philosophie III [Vorlesungen 1816-1832], Werke, vol. 20. Frankfurt/Main: Suhrkamp, 1986. - Vorlesungen über die Philosophie der Religion II [Vorlesungen 1821-1831], Werke, vol. 17. Frankfurt/Main: Suhrkamp, 1986. - Vorlesungen über die Geschichte der Philosophie I [Vorlesungen 1816-1832], Werke, vol. 18. Frankfurt/Main: Suhrkamp, 1986.

KANT, Immanuel. Critique of Judgement [1790], trad. Werner S. Pluhar. Indianapolis: Hackett, 1987. . Reflexionen zur Logik. Akademie-Ausgabe, Berlin: Reimer, 1914, XVI, 127 [Nr. 1820 a]).

SCHILLER, Friedrich. Kallias oder über die Schönheit. Briefe an Gottfried Körner In: FRICKE, Gerhard; GÖPFERT, Herbert G. (ed.). Sämtliche Werke. Munique: Hanser, 1980. v. 5 
. On the Aesthetic Education of Man in a Series of Letters. trad. R. Snell. Bristol: Thoemmes, 1994.

WELSCH, Wolfgang. Blickwechsel - Neue Wege der Ästhetik. Stuttgart: Reclam, 2012.

. Mensch und Welt. Eine evolutionäre Perspektive der Philosophie. Munique: Beck, 2012.

- Mundanus Homo - Jenseits der anthropischen Denkform der Moderne. Weilerswist, Velbrück Wissenschaft, 2012.

. Zur universalen Schätzung des Schönen, in Blickwechsel - Neue Wege der Ästhetik. Stuttgart: Reclam, 2012.

\begin{abstract}
Notas
${ }^{I}$ Artigo publicado em 23 de maio de 2014. Disponível em: $<$ http://contempaesthetics.org/newvolume/pages/article.php?articleID=701> Acesso em: 06 jun. 2014.

${ }^{2}$ Wolfgang Welsch, professor emérito, foi professor de Filosofia em diversas universidades alemãs e internacionais (Berlim, Jena, Stanford, Emory) e recebeu o Prêmio de Pesquisa Max Planck em 1992. Suas principais áreas de pesquisa são: epistemologia e antropologia, teoria da evolução, filosofia da cultura, estética e teoria da arte, filosofia contemporânea, Aristóteles e Hegel. Em publicações recentes, ele desenvolveu uma concepção estritamente evolutiva do ser humano, compreendendo tanto a evolução biológicaquanto a cultural.Em@il:wolfgang.welsch@uni-jena.de

${ }^{3} \mathrm{O}$ tradutor (em@il: vitorlranjos@yahoo.com.br) agradece ao autor Wolfgang Welsch e a Arnold Berneant, editor do periódico Contemporary Aesthetics (http://contempaesthetics.org/, ISSN 1932-8478), pela gentil permissão concedida por ambos para traduzir e publicar este texto para fins exclusivamente acadêmicos.

4 "Die Schöne Dinge zeigen um, dass der Mensch in die Welt passe" (Immanuel Kant, 'Reflexionen zur Logik,' Akademie-Ausgabe, Berlin: Reimer, 1914, XVI, 127 [Nr. 1820 a]). De acordo com Adickes, esta reflexão data de 1771-72, ou talvez de 1773-75.

${ }^{5}$ Cf. minhas publicações recentes: Blickwechsel - Neue Wege der Ästhetik (Stuttgart: Reclam, 2012), Mensch und Welt. Eine evolutionäre Perspektive der Philosophie (München: Beck, 2012), Mundanus Homo - Jenseits der anthropischen Denkform der Moderne (Weilerswist, Velbrück Wissenschaft, 2012).

${ }^{6}$ Immanuel Kant, Critique of Judgement [1790], trad. Werner S. Pluhar (Indianapolis: Hackett, 1987), p. 15.

${ }^{7}$ Ibid., p. 19.

8 "[...] a maneira de apresentar [o que ocorre] em um juízo de gosto é ter comunicabilidade universal subjetiva sem pressupor um conceito determinado; assim, essa comunicabilidade universal subjetiva não pode ser
\end{abstract}

Problemata: R. Intern. Fil. v. 5. n. 2 (2014), p. 388-404

ISSN 2236-8612 
nada mais que [a do] estado mental no qual estamos quando a imaginação e a compreensão estão em atuando livremente (na medida em que elas se harmonizam uma com a outra conforme seja necessário para a cognição em geral). Porque somos conscientes de que esta relação subjetiva adequada para a cognição em geral deve manter-se para todos, e assim ser universalmente comunicável, tanto quanto qualquer cognição determinada, já que a cognição sempre repousa sobre essa relação como sua condição subjetiva. Agora, esse juizo meramente subjetivo (estético) do objeto, ou da apresentação pela qual ele é dado, precede o prazer no objeto e é a base desse prazer, [um prazer] na harmonia dos poderes cognitivos" (Ibid., p. 62 [B 29, \& 9].

Georg Wilhelm Friedrich Hegel, Enzyklopädie der philosophischen Wissenschaften im Grundrisse I [1830], Werke, vol. 8 (Frankfurt/Main: Suhrkamp, 1986), p. 123 [\$ 46]; Hegel, Vorlesungen über die Geschichte der Philosophie III [Vorlesungen 1816-1832], Werke, vol. 20 (Frankfurt/Main: Suhrkamp, 1986), 385; Hegel, Vorlesungen über die Philosophie der Religion II [Vorlesungen 1821-1831], Werke, vol. 17 (Frankfurt/Main: Suhrkamp, 1986), p. 445.

${ }^{10}$ Hegel, Vorlesungen über die Geschichte der Philosophie I [Vorlesungen 1816-1832], Werke, vol. 18 (Frankfurt/Main: Suhrkamp, 1986), p. 405; vgl. ibid., p. 440.

${ }^{11}$ Johann Wolfgang Goethe, Sämtliche Werke nach Epochen seines Schaffens (Münchner Ausgabe), eds. Karl Richter et al., Vol. 19: Johann Peter Eckermann, Gespräche mit Goethe in den letzten Jahren seines Lebens, ed. Heinz Schlaffer (Munique: Hanser, 1986), 101 [14 de Abril de 1824].

${ }^{12}$ Para a tradução em inglês do texto de Schiller, eu usei, onde foi possível, com correções ocasionais, a seleção feita por William F. Wertz Jr. publicada em Fidelio, vol. I, n. 4, Inverno de 1992; em outros casos, é minha própria tradução. Os créditos se referem à seguinte edição alemã do texto: "Kallias oder über die Schönheit. Briefe an Gottfried Körner”, in: Friedrich Schiller, Sämtliche Werke, vol. 5, eds. Gerhard Fricke e Herbert G. Göpfert (Munique: Hanser, 1980), pp. 394-433.

13 Cf. Friedrich Schiller, "Kallias oder über die Schönheit. Briefe an Gottfried Körner", l.c., 410 [Carta de 23 de fevereiro de 1793].

${ }^{14}$ Deve ser uma regra "que ela [a entidade natural] impôs a si própria" (ibid., p. 417).

${ }^{15}$ Ibid., p. 419.

${ }^{16}$ A impressão de que a formação do objeto segue uma regra autoimposta leva, "de fato, necessariamente à ideia de determinação interna, ou seja, à liberdade" (ibid., p. 410). O objeto nos "compele" a "estar atento à sua propriedade de não ser determinado a partir do exterior” (ibid., p. 409).

"[...] a característica objetiva que permite que as coisas apareçam como livres é precisamente aquilo que, quando presente, lhes proporciona beleza e, quando ausente, destrói sua beleza" (ibid., p. 408).

18 "Então a beleza não é nada mais do que a liberdade na aparência" (ibid., p. 400 [Carta de 8 de fevereiro de 1793]. "A razão da beleza é, em toda parte, a liberdade na aparência" (ibid., p. 411 [Carta de 23 de fevereiro de $1793]$.

Problemata: R. Intern. Fil. v. 5. n. 2 (2014), p. 388-404

ISSN 2236-8612 
${ }^{19}$ A propósito, também para Schiller (como para Kant), antes de tudo é a beleza natural que importa, não a beleza da arte. Esta última "exige o seu próprio capitulo" (ibid. p. 416).

${ }^{20}$ Schiller enfatiza que "esta natureza e esta heautonomia são qualidades objetivas dos objetos aos quais eu as atribuo; pois elas permanecem delas, mesmo se o objeto representante for totalmente subtraido. A diferença entre dois seres da natureza - dos quais um é forma total e mostra um domínio perfeito da força vivente sobre a massa, enquanto o outro foi subjugado pela sua massa - permanece, mesmo após a completa suspensão do sujeito que julga" (ibid., p. $416 f$.).

${ }^{21}$ Ibid, p. 420 f., Schiller continua: "Se a jaqueta se danifica, por outro lado, então nós dois, ela e eu, perdemos a nossa liberdade. Por esta razão é que todos os tipos bastante apertados e bastante soltos de vestes têm igualmente pouca beleza; por não considerar que ambos limitam a liberdade de movimentos, assim o corpo em vestes apertadas mostra sua figura apenas à custa das roupas, e com roupas largas a jaqueta esconde a figura do corpo, no qual ela amplifica-se com a sua própria figura e reduz o seu mestre a seu mero portador" (ibid., p. 421).

${ }^{22}$ Ibid.

${ }^{23}$ Ibid., p. 425.

${ }^{24}$ Ibid.

${ }^{25}$ Ibid.

${ }^{26}$ Após Kant, Schiller entretanto diz “que nenhuma coisa no mundo sensual possui realmente a liberdade, mas só a possui aparentemente” (ibid., p. 409). No entanto, ele defende a objetividade da beleza, e seu argumento é o seguinte: "[...] como se pode procurar uma razão objetiva para essa ideia nos fenômenos? Esta razão objetiva deveria consistir em uma qualidade dos fenômenos que absolutamente nos obriga a levar adiante a ideia de liberdade em nós e a referi-la ao objeto" (ibid.). Então, Schiller está à procura de um caminho à objetividade da beleza não afetado pelas objeções kantianas.

${ }^{27}$ Ibid., p. 420.

28 Friedrich Schiller, On the Aesthetic Education of Man in a Series of Letters, trad. R. Snell (Bristol: Thoemmes, 1994), $27^{a}$ Carta, p. 137.

${ }^{29}$ Ibid., $27^{a}$ Carta, p. 140.

30 "Adesionismo pleno" pretende traduzir a palavra inglesa whateverism (literalmente, "qualquerismo"), que significa a aderência à seguinte afirmação: "Apoiaremos resolutamente quaisquer decisões políticas que Comandante Mao [Tsé-Tung] fez, e seguiremos com total lealdade quaisquer instruções que o Comandante Mao deu." Tal afirmação foi uma política defendida pelo presidente do partido comunista chinês Hua Guofeng, sucessor de Mao, em fevereiro de 1977, porém derrotada por sua impopularidade frente à proposta de reforma de mercado defendida por Deng Xiaoping e outros partidários. [N. do T.]

${ }^{31}$ Em 1792, a própria Assembleia Nacional Francesa outorgou cidadania honorária a Schiller.

${ }^{32}$ Da mesma forma, seu discurso estético dos artefatos é regido pela perspectiva de liberdade. Uma jaqueta é, como vimos, esteticamente correta quando possui e outorga a liberdade.

Problemata: R. Intern. Fil. v. 5. n. 2 (2014), p. 388-404

ISSN 2236-8612 
${ }^{33}$ Considere-se também que a evolução é, por princípio, não determinista, mas um processo que implica liberdade. Ela encontra ou gera uma resposta por múltiplas diferenciações e modos de auto-referência. Em última análise, até mesmo as leis da natureza, como as conhecemos hoje, podem não ser de validade universal, mas sim resultantes da evolução do nosso cosmos (cf. Wolfgang Welsch, Homo mundanus, loc. cit., pp. 855-857).

34 Cf. Wolfgang Welsch, "Zur universalen Schätzung des Schönen”, in Blickwechsel - Neue Wege der Ästhetik (Stuttgart: Reclam, 2012), pp. 292330.

${ }^{35}$ Cf. Friedrich Cramer, Chaos und Ordnung: Die komplexe Struktur des Lebendigen (Stuttgart: Deutsche Verlags-Anstalt, 1989), pp. 195-202. Ebenso: Friedrich Cramer e Wolfgang Kaempfer, Die Natur der Schönheit: Zur Dynamik der schönen Formen (Frankfurt/Main: Insel, 1992), pp. 264283.

${ }^{36}$ Eis uma passagem em que Schiller deixa claro que aparentemente as categorias puramente estéticas têm sentido próprio apenas como categorias de formação de padrão natural: "Conveniência, ordem, proporção, perfeição - qualidades nas quais por muito tempo se acreditava ter encontrado a beleza - não tem absolutamente nada a ver com isso. Onde, porém, a ordem, proporção, etc. pertencem à natureza de uma coisa, como no caso de qualquer coisa orgânica, lá elas são eo ipso invulneráveis, não para seu próprio interesse, mas porque são inseparáveis da natureza da coisa. Uma violação brutal da proporção é feia, mas não porque a percepção da proporção é bonita. Absolutamente não, mas sim por ser uma violação da natureza que indica heteronomia" (Schiller, "Kallias oder über die Schönheit”, l.c., p. 419 f. [Carta de 23 de fevereiro de 1793]).

37 Do período romântico ao filósofo contemporâneo John McDowell, assumiu-se que, após a degradação mecanicista da natureza do início e do fim do período moderno, precisamos de um "reencantamento da natureza." Só então o espírito e a natureza podem ser reunificados. Este reencantamento era esperado da religião, da filosofia, da literatura e das novas mitologias, mas não apareceu. Por isso as pessoas atualmente ainda se queixam de que esta aspiração não foi realizada e que estamos presos na situação antiga. Porém, aqueles que falam desse modo devem ter cochilado quando surgiram os conhecimentos da ciencia recente. Apenas isso pode explicar tal desconhecimento de que este "reencantamento" ocorreu há muito tempo, não só pelas instâncias nas quais se confiava, mas também, dentre todas, pela instância da qual não se esperava nada de bom e que, portanto, era ignorada: a ciência contemporânea. Esta deu-nos, de fato, um equivalente maravilhoso de "reencantamento", a saber, uma visão científica da natureza oferecendo tudo o que se pode desejar a fim de superar os velhos mecanismo e dualismo. Neste ensaio, tentei mostrar como a concepção estética de Schiller proporcionou bons meios para isso.

${ }^{38}$ Se Kant tivesse entendido a natureza dessa forma, ele poderia ter salvado a sua terceira crítica.

Problemata: R. Intern. Fil. v. 5. n. 2 (2014), p. 388-404

ISSN 2236-8612 